\title{
FILOSOFIAS E GÊNEROS: DESAFIOS PARA ENSINAR A FILOSOFAR
}

\section{PHILOSOPHIES AND GENDERS: CHALLENGES TO TEACH PHILOSOPHIZING}

\author{
Flávio de Carvalho ${ }^{1}$
}

Recebido em: 09/2020

Aprovado em: 10/2020

\begin{abstract}
Resumo: Este artigo indaga pelo kairós para se filosofar e para se ensinar a filosofar e reconhece o pensar como um ato político e de contraconduta. A discussão pretende compreender o que podem as Filosofias e o ensino de Filosofia diante dos desafios que a realidade contemporânea manifesta com o quadro de violência e discriminação que envolvem as identidades de gênero. $\mathrm{O}$ desafio de pensar um Brasil que é o país onde mais se mata pessoas da comunidade LGBTQI+ e onde o feminicídio também faz milhares de vítimas todos os anos. Há também o desafio de reconhecer as questões de gênero como objeto de problematização filosófica, com implicações ontológicas, estéticas e éticas (ambas políticas), e por conseguinte o desafio de construir o lugar para tais questões no Ensino de Filosofia. Outros desafios tratados remetem ao lugar (ou não-lugar) das filósofas na história da Filosofia e no livro didático de Filosofia, e também remete ao problema da linguagem e seu aspecto sexista (machista). No final, o texto nos provoca a pensar as microcolinialidades e as microcontracondutas atinentes à gênero e à raça.
\end{abstract}

Palavras-chaves: Gênero, Ensino de Filosofia, Educação Filosófica, microcolonialidade, microcontraconduta.

\begin{abstract}
This article asks about the kairós to philosophize and to teach philosophizing and it also recognizes thinking as a political and counter-conduct act. It aims to understand what Philosophies and Teaching Phylosophy can do in view of the contemporary reality challenges in their context of violence and discrimination that involve gender identities. It's a challenge to think about Brazil because it's the country (the first one in the world) where hundreds of LGBTQI+ community members are murdered and where femicide also makes thousands of victims every year. There is also a challenge to recognize the gender issues as an object of philosophical problematization, with their ontological, aesthetic and ethical implications (also political), therefore the challenge of addressing these issues in Teaching Philosophy. Some challenges refer to the place (or non-place) of women philosophers in the history of Philosophy and in the Philosophy manuals and it also refers to the problem of sexist and chauvinist language. At the last, text provokes thinking about the microcolinialities and the microcontraconducts related to gender and race issues.
\end{abstract}

Keywords: Gender, Teaching Philosophy, Philosophical Education, microcoloniality, microcounter-conduct.

\footnotetext{
${ }^{1}$ Flávio José de Carvalho é doutor em Filosofia, professor do Curso de Graduação em Filosofia e do quadro de docentes permanentes do Mestrado Profissional em Filosofia, núcleo UFCG. E-mail: flavio.carvalho@ufcg.edu.br
} 


\section{Considerações Iniciais}

Qual é o kairós para a Filosofia? Esta pergunta acerca do momento oportuno para se filosofar inspira e percorre as páginas deste artigo, que tem pretensão mais de dialogar com a leitora e com o leitor do que trazer informações ou discussões filosóficas inéditas. Ocupar-se com o quando filosofar? traz inerente a si a questão o que pode o filosofar?, questionamento que também acompanha a escrita deste artigo. A Filosofia é herdeira de seu tempo e o filosofar se manifesta por meio de pessoas e de seus corpos, por meio de subjetividades construídas por tramas social-históricas, por meio de relações intersubjetivas que necessitam de diálogo, ainda que, contemporaneamente, no Brasil e em várias partes do mundo, haja discursos e atitudes sociais, econômicas e políticas que ordenem e comandem o silenciamento e o esquecimento.

Qual é o kairós para falar da relação entre Ensino de Filosofia e as Questões de Gênero? E, igualmente, o que pode o filosofar frente às demandas sociais que envolvem as dificuldades, os confrontos, as violências, mas também a autoafirmação, o empoderamento e a conquista do lugar de fala intelectual da diversidade de pessoas e seus diferentes modos de ser, seus diferentes modos de existir e manifestar sua sexualidade?

Os vários paradigmas interpretativos da realidade (oriundos das ciências, das filosofias, das artes, das teologias, dos sensos comuns) constroem e mantêm projetos de realidades. Porém, paradigmas interpretativos também deslocam, destroem e recriam realidades. Neste sentido, reconhecemos que estamos vivendo um momento social-histórico de colapso dos paradigmas identitários, universalistas, unidimensionais e unilaterais, desse modo, emergem discursos e posturas interpretativas outras que falam de realidades outras possíveis, que reconhecem a singularidade das pessoas e suas diversas formas de existir e de se identificar (trata-se, mais que isso, de se autoidentificar), que reconhecem a circunscrição espaço-temporal-cultural das interpretações e nos fazem pensar na limitação imposta pelo esquadro das teorias de totalidade, que reconhecem a necessidade dos saberes se construírem em diálogo epistêmico interseccional, isto é, combinar objetos e objetivos, problemas e métodos, conceitos e intervenções quando se pretende compreender os inumeráveis fenômenos da vida, da existência e da realidade social-histórica.

Além desta situação que engloba a construção dos saberes e que reverbera em discussões ontológicas, éticas, políticas e educacionais, podemos reconhecer o kairós para o filosofar e 
para a Filosofia (as Filosofias) tratar das Questões de Gênero quando o responsável por uma pasta ministerial, que deve tratar da educação das cidadãs e dos cidadãos do Brasil, afirma que o homossexualismo - ignorando ou querendo (ideologicamente) ignorar a desatualização científica que o uso deste termo implica - está associado a famílias desajustadas.

Podemos reconhecer o kairós para o filosofar quando se vive no país onde mais se mata pessoas das comunidades LGBTQI+, e o espanto filosófico deve ser acentuado se a cifra destes assassinatos cometidos no Brasil considerar a intersecção gênero, raça e classe social. $\mathrm{O}$ feminicídio apresenta números alarmantes, são milhares de mulheres vítimas de assassinatos todos os anos. O espanto filosófico também se acentuará se considerarmos a intersecção mencionada. Em ambos os casos, a intersecção escancarará a desigualdade social, a discriminação racial e o machismo constitutivos da formação do povo brasileiro.

Podemos ainda reconhecer o kairós para o filosofar quando documentos oficiais importantes para a condução da educação em nível nacional, como por exemplo, a Base Nacional Comum Curricular (BNCC) não inclui - e assim, intencionalmente, exclui - o tratamento das questões que envolvam as identidades de gênero, e também retira - e assim, intencionalmente, exclui - o lugar epistêmico específico do componente curricular Filosofia, ainda que o considere fazendo parte da área de Ciências Humanas e Sociais Aplicadas.

Diante do exposto, o kairós para a Filosofia e para o filosofar é agora. Nós, filósofasdocentes e filósofos-docentes, precisamos reconhecer que também é o kairós para ensinar a filosofar, pois temos o compromisso epistêmico, educacional e ético-político de nos inserirmos nestas situações acima indicadas (e em muitas outras) e as tratarmos como problemas filosóficos em sala de aula. Neste sentido, o artigo que apresentamos à leitora e ao leitor pretende oferecer algumas compreensões construídas a partir de nossa vivência como cidadão brasileiro, de nosso filosofar e ensinar a filosofar, e, sobretudo, este texto quer provocar o pensamento, compreendendo que pensar é um ato político e contém a potência de ser uma contraconduta.

\section{Desafios e questões para filosofarmos}

A Filosofia é herdeira de seu tempo. Por mais que esta afirmação de uma parte pareça uma obviedade e de outra parte pareça apenas um apelo retórico, o seu uso aqui pretende indicar duas condições inerentes ao movimento de filosofar e à construção do saber filosófico: 1. a Filosofia deve ter atenção às situações que a vida social-histórica dos homens ... digo, que a 
vida social-histórica dos homens e das mulheres ... digo, que a vida social-histórica dos seres humanos constroem e que devem ser reconhecidas e assumidas como demandas para o filosofar, ou seja, devem ser reconhecidas e tratadas como problemas filosóficos, portanto; 2. a Filosofia, como herdeira, deve cuidar dos seres humanos e de suas criações social-históricas, deve dedicar-se ao exercício de compreender cada uma destas criações, questionando as múltiplas origens de cada criação, ocupando-se com suas manifestações e variações, dedicando-se a construir um discurso ao mesmo tempo interpretativo e proposito - interpretativo enquanto fabrica conceitos, compreensões que respondem às questões problemáticas atinentes a estas criações sociais, propositivo enquanto funciona como modo de intervir sobre a realidade em que se inserem estas criações sociais, realizando críticas, desnaturalizando ideias e atitudes, recriando a realidade. Em todas as Filosofias há, portanto, uma pedagogia do cuidado epistêmico e estético com a realidade, com os saberes e as criações que se vinculam à existência e à vida em suas múltiplas formas de manifestação.

Se a leitora ou o leitor não concordam com esta argumentação, isto evidencia que estamos falando de Filosofias diferentes, com o que concordo e corroboro afirmando, então, "as Filosofias são herdeiras de seu tempo" e aqui não se trata de mera mudança gramatical para a forma plural, antes, trata-se de reconhecer que no mesmo tempo histórico podem existir e coexistir diversos e diferentes modos de filosofar, portanto, filosofares e Filosofias.

É sobre isto que trataremos no texto que ora apresentamos, sobre o dever de cuidar inerente ao saber filosófico e que por vinculação epistêmica se estende à educação filosófica, isto é, ensinar a filosofar como atitude autônoma e apropriada (o filosofar e aquilo sobre o que se filosofa são tornados próprios para o indivíduo que filosofa), que implica em reconhecer e assumir o cuidado epistêmico e político com a diversidade de ideias, seres e situações que constituem a realidade social-histórica. Na presente oportunidade, filosoficamente, cuidaremos da relação entre as questões de gênero e o ensino de Filosofia, questionando assim o que podem as Filosofias diante desta demanda emergencial, assumindo para nós, filósofas e filósofos, uma necessidade que outros campos do saber vêm tratando há mais tempo e que não podemos mais hesitar em cuidar, desta feita como problema filosófico. Trata-se de cuidar de desafios.

Um desafio que talvez por questões de método de raciocínio e escrita preceda os outros diz respeito ao reconhecimento do gênero como problema filosófico. O que esta questão comporta que a torna atraente e desafiadora para o olhar filosófico? Aquele olhar que se espanta, que se desloca e desnaturaliza tudo e todos, e enquanto isso recria não apenas o dizer sobre a 
realidade, mas ela própria sofre esta intervenção. O que esta questão comporta que a torna um problema filosófico? Talvez seja o fato que as questões de gênero, isto é, as questões que envolvem os diversos modos de ser e de viver a sexualidade humana têm implicações ontológicas, éticas e estéticas (ambas políticas). Sexualidade, aqui, entendida em seu sentido mais lato possível, ou seja, sem limitá-la ao aspecto da eroticidade, e de forma alguma reduzindo-a ao aspecto da composição biológica do corpo com o qual se nasce. Sexualidade como condição constitutiva da existência dos seres humanos, como manifestação de identidades, de desejos, de vontades, de visões de mundo, de saberes e de discursos, de autoreconhecimento políticos, de fruições e de eróticas. Tratar de gênero não é tratar de sexo. A partir desta compreensão de sexualidade, portanto, as questões de gênero mobilizam o pensamento acerca da existência de diversos e diferentes modos de ser, modos de existir como pessoa, modos de viver em um ecossistema dinâmico, requerendo, portanto, o cuidado epistêmico das Filosofias para compreender esses diversos e diferentes modos de Ser.

As questões de gênero terminam por mobilizar o pensamento acerca da existência de diversas e diferentes visões de mundo, que se manifestam em uma pluralidade de modos de dizer e de agir sobre a realidade. Durante muito tempo não se tratou (se negou) a implicação entre o agir ético e político e as variações de gênero, com base na compreensão da universalidade de princípios da Ética que se espelhariam nas questões da Política. Todavia, como manter este entendimento quando existem provocações oriundas da vida concreta das pessoas que indicam para a singularidade da existência de todos e de cada um dos seres humanos, como uma ética universalista pode dar conta deste fenômeno? Não estaríamos em um momento de colapso de éticas universalistas? O reconhecimento da coexistência de Filosofias coloca a necessidade de pensar na coexistência de Éticas.

As questões de gênero igualmente terminam por mobilizar o pensamento acerca da existência de diversos e diferentes modos de sentir e de criar a realidade e de se sentir e de se criar. Sentir a realidade é cria-la ou criar uma de suas facetas, uma de suas dimensões, sentir o próprio corpo é já criá-lo ou criar uma de suas performances, manifestar esteticamente o que se sente na vivência da realidade e do seu próprio corpo é, portanto, um problema filosófico. Assim sendo, a pluralidade de modos de ser e de viver a sexualidade reverbera em diversos e diferentes modos de sentir, criar e manifestar a realidade. A criação e a fruição estética são formas de criar realidades possíveis. Quantas realidades possíveis se manifestam na diversidade de sexualidades? 
Compromisso análogo tem o Ensino de Filosofia, isto é, as demandas oriundas das criações social-históricas devem fazer parte dos interesses desse campo epistêmico que se ocupa com o filosofar enquanto vivência (experiência de pensar) no processo de ensinoaprendizagem, seja na formação integral das(os) jovens na escola seja na formação profissional das pessoas nas instituições de Ensino Superior - na graduação e na pós-graduação. Neste sentido, mais um desafio se mostra, pois as Questões de Gênero precisam estar presentes na elaboração das estruturas curriculares, também nos livros didáticos e como bibliografia principal nas pesquisas, divulgando o trabalho intelectual de todas $\mathrm{e}$ de todos, independentemente de seu gênero, e por fim, são questões que devem ser pensadas e tratadas segundo metodologias de ensino específicas.

Para que esta proposição se efetive é, todavia, necessário que se discuta e se ultrapasse dois obstáculos importantes: o primeiro ao qual nos referimos acima, diz respeito ao reconhecimento das questões de gênero como problema filosófico, que implica em discutir as condições de possibilidade de uma ideia, teoria ou situação ser tomada como objeto para um ou para vários campos do saber filosófico; o segundo diz respeito ao conservadorismo ou certa pudicícia que acompanha a história da educação brasileira, principalmente, no que diz respeito à educação de crianças e adolescentes, e que é disseminado nos discursos e em certas atitudes governamentais do atual governo federal. A formação educativa integral de crianças e adolescentes precisa se ocupar, deve cuidar, também das questões que envolvem o conhecimento e o autoconhecimento da corporeidade e da sexualidade em todas as suas diversas e diferentes formas de existir.

Note-se que depois de um período de relativa abertura para as discussões de gênero na formação escolar da juventude brasileira, exemplificado pela publicação dos Cadernos SECAD 4, que trata de "Gênero e Diversidade Sexual na Escola: reconhecer diferenças e superar preconceitos”, material publicado em 2007 durante o governo do Presidente Luís Inácio Lula da Silva e na atuação do Ministro da Educação Fernando Haddad, documento oriundo da Secretaria de Educação Continuada, Alfabetização e Diversidade, posteriormente renomeada para Secretaria de Educação Continuada, Alfabetização, Diversidade e Inclusão - secretaria que foi extinta em uma das primeiras decisões do primeiro dos quatro ministros da pasta ministerial da educação que o atual governo nomeou, em aproximadamente um ano e meio de mandato, até o presente momento.

Convém esclarecer que o conservadorismo e a pudicícia mencionadas já se mostraram 
quando das discussões sobre o texto da Base Nacional Comum Curricular (última versão publicada em 2019), cujo texto final não pode utilizar os termos ou incluir as questões de orientação sexual. Portanto, a discussão das questões de gênero no ensino da Filosofia em princípio não tem apoio na $\mathrm{BNCC}$, todavia, as Filosofias em seu caráter questionador e propositivo sobre tudo e sobre qualquer coisa têm a capacidade legitimidade epistêmica de perguntar em sala de aula: por que as questões de orientação sexual foram excluídas da BNCC? Quais as influências ideológicas e políticas que esta exclusão pode revelar? E pela colocação de tais perguntas, por uma questão de método, ter-se-á que se perguntar O que é o gênero e o que é orientação sexual? Como sempre, ao questionar a razão pela qual "isto não pode" já se está em atitude de filosofar. Em síntese, os dois obstáculos mencionados implicam em movimentos de abordagem sobre a questão de tratar de gênero no Ensino de Filosofia (campo do saber) e sobre tratar também no ensino da Filosofia (componente curricular), pensando os problemas epistêmicos, pedagógicos e políticos envolvidos na questão. Seguindo esta pauta dupla, construímos um itinerário de discussão que nos conduzirá para outros desafios, senão vejamos.

“Tem mulher filósofa?” Esta arguição foi dirigida a mim diversas vezes durante meus anos de docência. Estudantes (elas e eles) me perguntavam sobre mulheres que escreveram textos, mulheres que criaram conceitos, mulheres que foram excluídas da História da Filosofia no Ocidente. Colocando a questão de outro modo, aquelas e aqueles estudantes me perguntavam sobre qual o lugar das mulheres na história da Filosofia? Até bem pouco tempo, um primeiro momento a se relatar, os nomes lembrados eram pouquíssimos, como popularmente dizemos "cabia nos dedos de uma mão e sobravam dedos". Talvez a mais lembrada e lida fosse Hannah Arendt, seguida por Simone de Beauvoir. E isto é importante destacar, lembrar o nome e não se ler o trabalho intelectual, pouco contribui para o movimento de inclusão dos pensamentos de filósofas no âmbito das discussões e das pesquisas e produções bibliográficas em Filosofia.

O segundo momento deste relato indica um tempo mais recente e que permanece até os dias atuais, no qual se trouxe para a memória, para a leitura e discussão de seus pensamentos, filósofas como Hipatia de Alexandria que viveu no século quinto da era cristã, também Cristina de Pisan que viveu entre os séculos XIV e XV e escreveu “A Cidade das Mulheres”, e do século XVIII trouxe Mary Wollstonecraft que escreveu "A reivindicação dos Direitos das Mulheres" e já do século XX, a autora de "A acumulação do capital”, Rosa Luxemburgo. Note-se que aqui fizemos um pequeno recorte para cobrirmos um período temporal amplo, todavia o número de 
filósofas trazidas à memória, lidas e discutidas é muito maior e pesquisas contemporâneas têm auxiliado neste resgate e divulgação de suas vidas e obras.

O terceiro momento, também acontecendo na contemporaneidade, diz respeito à valorização da leitura e discussão de textos de filósofas que estão em atividade filosófica atualmente, ou seja, mulheres que revelam aos olhares contemporâneos o movimento de filosofar feito a partir de modos de ser mulher, de vozes de mulher. Aqui não falamos em Filosofia feminina, mas Filosofia feita por mulheres, cuja semântica não carrega os estereótipos que historicamente se acumularam e assim condensaram o "modo feminino" de ser e viver. Estas filósofas estão em vários países do mundo como Angela Davis nos EUA, Gisèle Szczyglac na França, Fatma Chamakh-Haddad na Tunísia, Ester Díaz na Argentina e Marilena Chauí no Brasil. À guisa de breve digressão, percebemos que, atualmente, assumir-se como filósofa ou filósofo, reconhecer pessoas (vivas) que filosofam, tem sido uma prática frequente, o que está fazendo mudar também certo pudor cultivado, notadamente na academia de Filosofia no Brasil, que entendia que a denominação de "filósofo" cabia a poucos, sendo apenas possível se nomear de "professor de Filosofia" ou de "estudioso da Filosofia". Ora, mas o que faz de alguém filósofa ou filósofo é sua capacidade de desenvolver um trabalho diuturno com as Filosofias, com sua Filosofia, que envolve a ocupação com a pesquisa, abrange o ensino e se manifesta nas publicações. A leitora e o leitor devem ter notado que esta digressão nos remete a outro obstáculo a ser superado, com o qual não nos envolveremos neste momento, mas que merece aquele olhar filosófico questionador que resulta em perguntar " $\mathrm{O}$ que torna alguém filósofa ou filósofo?”, “O que é uma filósofa ou um filósofo?”

Ainda neste terceiro momento de discutir a partir das vozes de mulheres, reconhecemos a emergência e a visibilidade do pensamento intelectual das mulheres trans e das travestis, as quais rompendo os preconceitos, estereótipos e tradições excludentes vêm desenvolvendo pesquisa, ensinando e divulgando conhecimento científico por meio de publicações e realizando formação em todos os níveis acadêmicos, das quais destacamos a presença e o lugar de fala intelectual de Danieli Christovão Balbi, a primeira mulher trans a obter o título de doutora (Letras - Ciência da Literatura) na Universidade Federal do Rio de Janeiro, onde atualmente leciona, e também de Sarug Dagir Ribeiro, doutora em Psicologia pela Universidade Federal de Minas Gerais, instituição na qual também atuou como professora, e igualmente, destacamos a presença e o lugar de fala intelectual de Luma Nogueira de Andrade, a primeira travesti a obter o título de doutora (em Educação) pela Universidade Federal do Ceará, e atualmente 
leciona na Universidade da Integração Internacional da Lusofonia Afro-Brasileira (UNILAB) e, também, de Megg Rayara Gomes de Oliveira, a primeira travesti negra a obter o título de doutora (em Educação) no Brasil, tendo feito seu doutorado na Universidade Federal do Paraná, onde, atualmente, leciona. E desse modo, a presença e o lugar de fala intelectual destas pessoas, historicamente invisibilizadas no Brasil, vem ampliando-se e assumindo a diversidade e a diferença inerentes aos diversos e diferentes modos de ser das pessoas. Lamentamos não poder incluir neste relato os nomes de mulheres trans e travestis que desenvolvam pesquisas, ensino e publicações no âmbito da Filosofia. Buscamos referências em vários materiais disponíveis na internet, acionamos nossos contatos com pesquisadoras e pesquisadores do Brasil, e lamentavelmente não conseguimos identificar a presença e o lugar de fala intelectual de mulheres trans ou travestis que atuem como filósofas ${ }^{2}$.

Estas diversidade e diferença precisam chegar ao Ensino de Filosofia, e que as pesquisas e as publicações filosóficas ocupem-se cada vez mais com a emergência de falas outras, de discursos que deslocam os eixos tradicionais de compreensão metodológica da construção dos saberes, de vozes que reivindicam falar por si em vez de apenas serem faladas por outrem. Note-se que não é necessário inviabilizar ou vetar que a investigação e a discussão possam ser realizadas por pessoas que têm outro modo de ser (outro gênero) ou que não vivem a violência do preconceito de gênero. A solidariedade radical, o reconhecimento do outro em sua diferença radical precisa ser cultivado no território da produção intelectual, que por vezes se torna insensível e apática aos clamores da vida social vivida nas ruas, sob a falsa alegação da neutralidade (epistêmica e política) do fazer científico.

Enquanto este deslocamento de olhar e de ações não se realizar de modo intenso, nossos livros didáticos de Filosofia permanecerão revelando uma ausência importante no que diz respeito às discussões de gênero e ao trabalho das filósofas de todas as épocas históricas, inclusive a atual. Aqui nos referimos aos livros didáticos de Filosofia constantes na ultima edição do Programa Nacional do Livro Didático (PNLD), em 2018. Não afirmamos que os livros didáticos de Filosofia não tratam ou não mencionam as questões de gênero ou o pensamento de filósofas, questionamos a proporcionalidade que estes elementos discursivos ocupam nos referidos livros. As autoras e os autores tratam estes elementos, na maioria das

\footnotetext{
${ }^{2}$ Como autor deste artigo, reconhecendo que pesquisar é um ato contínuo e realizado por várias mãos, solicito que se a leitora ou o leitor tiverem referências sobre mulheres trans ou travestis que atuem na área de Filosofia, por gentileza, façam contato pelo email flavio.carvalho@ufcg.edu.br. Considero relevante também ter informações sobre estudantes de graduação e de pós com este perfil. Desde já, sou muito agradecido.
} 
vezes, de modo indireto, transversal, não oferecendo, todavia, impedimentos para que as professoras e os professores de Filosofia possam fazer aportes mais diretos e incisivos no dia a dia de suas aulas. Destacamos, entretanto, o trabalho realizado no livro didático "Reflexões: Filosofia e Cotidiano" de José Antônio Vasconcelos, que dedica uma unidade do livro para tratar de Filosofias para além dos recortes costumeiros, e assim, se ocupa com as Filosofias orientais, as Filosofias africanas e afrodescendentes e as Filosofia feministas. Precisamos de mais espaços epistêmicos e políticos como esses em nossos livros didáticos, em nossas salas de aulas, na escola e nos cursos universitários de Filosofia no Brasil. Falando de modo prático, o ultrapassamento deste obstáculo passa pelo comprometimento que cada uma(um) de nós, filósofas-professoras e filósofos-professores, assumamos a tarefa de vincular um número maior de referências, de vozes filosóficas, aos tradicionais e importantes problemas e referências da Filosofia, e que este aumento numérico oportunize o trabalho com a presença e o lugar de fala intelectual de pessoas, diversas e diferentes.

O último desafio que nos ocuparemos neste artigo remete à questão do uso da linguagem. Além de ser uma das formas possíveis de comunicação e de confronto entre as pessoas, de servir como um dos meios possíveis de perpetuação de uma tradição e de instituição de uma revolução, o discurso linguístico é um importante elemento de formar, conformar, mas também de desconstruir compreensões sobre as identidades de gênero. De modo que a linguagem, ultrapassando a questão gramatical, é um instrumento político importante na construção da vida social. Sem a pretensão de nos imbuirmos em problematizações filosóficas acerca do fenômeno da linguagem, tampouco de fazermos incursões semióticas, nos ocupamos da linguagem nesta etapa do texto tendo em vista problematizar o lugar que as questões de gênero ocupam nos discursos das pessoas, em que medida o dizer linguístico é uma construção sexista que pode reforçar os androcentrismos que têm acompanhado a ciências, as arte, as religiões, as filosofia e tantos outros discursos e saberes. Uma última delimitação necessária: aqui tratamos do discurso linguístico construído a partir das estruturas da Língua Portuguesa.

Todavia, à guisa de referência histórica, na Língua Francesa desde o século XVIII se justificava a prevalência do gênero masculino sobre o feminino por meio de um pensamento que remonta ao linguista Nicolas Beauzée para quem o masculino é considerado mais nobre do que o feminino por causa da superioridade do homem sobre a mulher. Do século anterior vem outra justificativa, esta do gramático Scipion Dupleix para quem o gênero masculino é mais nobre e por isso ele prevalece sobre dois ou mais femininos, ainda que estes estejam mais 
próximos do seu adjetivo. Em Língua Portuguesa não temos registro de um lema como este, porém, desde as primeiras lições gramaticais sobre gênero e sua concordância na construção dos enunciados as e os estudantes recebem a orientação de concordar o gênero do artigo (definido ou indefinido) com o substantivo, regra que se aplica igualmente ao adjetivo, de modo que teremos "a casa é bonita" e "o chão está limpo". Mas, e se tivermos dois substantivos com classificação de gênero diferente? Questionando a frase "o menino e a menina são belos", por que gramaticalmente não se pode utilizar o adjetivo "belas"? De modo análogo, questionamos o porquê ao se dirigir a uma plateia composta por 99 mulheres e 1 homem, se utilizará o gênero masculino como referência no pronunciamento. Questões como estas, que ocupam linguistas, sociólogas e sociólogos, historiadoras e historiadores, também precisam ser tratadas por nós, filósofas e filósofos. E para o exercício da docência em Filosofia esta é uma atividade premente, uma vez que o discurso filosófico tem a capacidade de manter ou de desconstruir ideias, posturas e ações (inclusive as linguísticas). Estas situações dão o que pensar!

Se falamos em ausência de referência a pensadoras na História da Filosofia, nos currículos de ensino de Filosofia, nos livros didáticos de Filosofia, precisamos pensar ausência análoga na construção do discurso. Certa vez, ouvi uma jovem filósofa afirmar "eu sou muito mais do que um a entre parênteses", referindo-se ao uso costumeiro do elemento "(a)" após a aparição de um artigo, substantivo, adjetivo, forma verbal, os quais são grafados, geralmente, utilizando o gênero masculino. Esta afirmação dá o que pensar!

Reiteramos, a Filosofia é herdeira de seu tempo. Sendo assim, nos causa "espanto" e por isso nos interessa "pensar sobre" os seguintes fenômenos: há alguns anos, não muitos, temos observado seja em textos escritos seja em falas - acadêmicas e não acadêmicas, em situações formais e também nas informais - o uso das terminações "a" e "o). Desse modo, diz-se "estimadas leitoras e estimados leitores", diz-se também "o trabalho intelectual de filósofas e de filósofos" e somam-se as repetições, que a despeito de comprometerem em certa medida o fluxo da escrita, da leitura e da fala, e também de aumentar "desnecessariamente" a quantidade de carácteres digitados, todavia, manifesta um posicionamento político de crítica e de desconstrução de paradigmas e convenções que se manifestam pela linguagem; há alguns anos, não muitos também, temos notificado em textos informais o uso de sinais gráficos em substituição aos elementos "A" e "O" na composição de palavras. Desse modo, diz-se "esta discussão filosófica se dirige a todxs", diz-se também "na condição de pensador@s crític@s e engajad@s”. Não temos registro deste artifício linguístico (e político) sendo utilizado em textos 
formais ou acadêmicos, todavia, o fato é que um recado está sendo dado por meio destes usos linguísticos; por fim, há também não muitos anos, tem-se praticado a substituição dos elementos “A" e "O" na composição de palavras pelo "E”. Com isso tem-se "querides estudantes" e dizse também "esta ação requer compromisso de todes". Tudo isso dá o que pensar!

Não obstante as dificuldades com a correção ortográfica, de compreensão vocabular e mesmo com a pronúncia que tais artifícios promovem, "coleges" e "crítices" conflituam com as regras de vogais que acompanham G e C, “cidad@s" (para substituir "cidadãs/ãos") e ainda “todxs" que são impronunciáveis na língua portuguesa. Estes eventos dão o que pensar para nós, filósofas e filósofos - e a leitora e o leitor devem ter observado durante a leitura do texto que nossa redação antecede sempre a forma feminina à masculina, contrariando um corriqueiro hábito da forma masculina vir antes da feminina. Todas estas situações devem nos causar espanto e desejo de saber "por que estes eventos estão ocorrendo no âmbito da linguagem?", e também, "quais reverberações estes eventos compartilham com questões ontológicas", e ainda, “em que medida estes eventos manifestam ideias e posturas políticas". Tudo isto dá o que pensar e precisa ser tratado nas aulas de Filosofia, pois os sujeitos pedagógicos que lá estão, as e os estudantes vêm se deparando com tais eventos e mesmo fazendo uso dos artifícios mencionados.

\section{Considerações Finais}

Terminar a escrita de um artigo é tarefa sempre difícil, quer pela inconclusibilidade de qualquer discurso quer pelas novas demandas que terão surgido quando a leitora e o leitor do futuro tiverem interesse e acesso ao texto escrito no agora. Não escrevemos para qualquer hoje, mas para nosso hoje. Diante desse fato, optamos por encerrar nossa discussão, propondo duas questões que têm pertinência constante. Trata-se de um convite para continuar a filosofar sobre a vida cotidiana em que nos deparamos com situações que envolvem relações e identificações de gênero.

Convite para filosofar quando se ouve ou se recebe pelas mídias sociais aquela anedota ou aquele meme que reforça as padronizações heteronormativas sobre a mulher, sobre a lésbica, sobre a nordestina, sobre o travesti, sobre a negra, sobre o índio, sobre a idosa, sobre o pobre. Basta se perguntar: há alguma pessoa sendo atingida direta ou indiretamente em sua dignidade existencial e cidadã com esta mensagem? E daí assumir o que chamamos de microcontracondutas, ou seja, ações cotidianas de ruptura com os discursos e atos de exclusão 
social. Mas, as microcontracondutas precisam, principalmente, ter um viés propositivo, isto é, devem promover uma ação de promoção daquelas pessoas agredidas pela anedota ou pelo meme. Então, se indignar com o conteúdo é importante, questionar respeitosamente quem enviou também o é, quebrar a corrente de transmissão e de reprodução da mensagem é imprescindível, mas, sobretudo, deve-se elaborar uma fala (história ou meme) que evidencie as qualidades, a importância daquela pessoa - discriminada - para a vida social, o direito a ser quem se quer ser, tudo isto e o que mais for possível indicar, que está representado naquela pessoa, outrora agredida. Não basta ser antiviolência tem que ser pacifista, não basta não ser fascista tem que ser anti-fascista.

Convite para filosofar sobre comportamentos discriminatórios, sobre discursos preconceituosos, sobre pensamentos que constroem associações apressadas e exclusões, sobre crenças religiosas que dividem as pessoas entre os corretos e eleitos e os incorretos e condenados, filosofar sobre falas que transmitem mensagens as quais, eventualmente, pronunciamos e não temos consciência que por meio delas reproduzimos processos de dominação e de exclusão, de perpetuação de colonialidades oriundas de culturas autoproclamadas superiores, de aniquilamento de tradições cujas origens históricas são desconhecidas, intencionalmente esquecidas. Nós, brasileiras e brasileiros, assujeitadas e assujeitados pela colonização e pela colonialidade, em muitas situações não reconhecemos que construímos nossas microcolonialidades, que dominam e excluem os saberes, as identidades e as existências de pessoas que dividem o mesmo território geográfico e a mesma temporalidade histórica, e com quem não se compartilham a valorização de seus modos diversos de ser e os direitos civis atinentes. Trata-se, em resumo, de filosofar sobre nossas posturas microcoloniais perante os povos ancestrais das florestas, sobre as pessoas afrodescendentes, sobre as pessoas de regiões geopolíticas do Brasil historicamente exploradas e excluídas, e construir microcontracondutas que podem começar pela escuta atenta dos saberes ancestrais, trazendo as falas de indígenas, de quilombolas, de ciganas e ciganos, de sertanejas e sertanejos para as mesas de debate na Academia, dialogar a partir de seus lugares de fala; microcontracondutas que acrescentam (inclusão) nas aulas de Filosofia de jovens estudantes - ainda que a estrutura curricular não aborde, ainda que os documentos oficiais não indiquem - o estudo dos pensamentos, das Filosofias, originárias das Américas Latinas e das Áfricas, considerando seu modo específico de se construir sem a comparação com o esquadro ou a chancela de uma Philosophia. 